\title{
Developing hot air-assisted radio frequency drying protocols for in-shell walnuts
}

\author{
Bo Zhang', Ajuan Zheng', Liyang Zhou', Zhi Huang', Shaojin Wang',2* \\ ${ }^{1}$ Northwest A\&F University, College of Mechanical and Electronic Engineering, Yangling, Shaanxi, China, ${ }^{2}$ Department of Biological Systems \\ Engineering, Washington State University, L.J. Smith Hall, Pullman, WA, USA
}

\section{A B S T R A C T}

\begin{abstract}
Radio frequency (RF) drying is a rapid dehydration technique that can be applied to preserve perishable agricultural products. The objective of this research was to develop hot air-assisted RF (HARF) drying protocols for in-shell walnuts. A pilot-scale, $27.12 \mathrm{MHz}, 6 \mathrm{~kW}$ RF unit was used to study the drying process, including drying curves, drying kinetic models, and quality changes during RF drying and storage. Results showed that an electrode gap of $18.0 \mathrm{~cm}$ combined with hot air temperature of $50^{\circ} \mathrm{C}$ provided an acceptable heating rate and stable sample temperatures during RF drying. Total drying times to reduce the whole walnut moisture content from 20 to $8.0 \%$ on dry basis required 240 and 100 min using hot air (HA) drying and HARF drying, respectively. The drying curve for HARF heating was fitted to five different kinetic models, and the best one was the Page model with $R^{2}=0.998$. Quality analysis showed that there were no significant differences in peroxide value, free fatty acid, and colour between RF treatments and untreated controls during drying and storage periods $(P>0.05)$. RF heating can, therefore, provide a practical and effective method for drying in-shell walnuts with acceptable product quality.
\end{abstract}

Keywords: Walnuts; Radio frequency; Drying curve; Kinetic models; Quality

\section{INTRODUCTION}

Walnut (Juglans regia L.), a member of the Juglandaceae family, is mostly cultivated in the countries of Northern hemisphere, such as China, USA, Iran, and Turkey. China produced about 1.7 Mt of walnuts in 2013, which was approximately $50 \%$ of the world's walnut production (FAOSTAT, 2014). Walnut kernels are nutrient-rich food mainly due to its high biological-value proteins (low lysine/arginine ratio), high levels of oil (60 g/100 g on average mainly polyunsaturated fatty acids, PUFA) and antioxidants (phytosterols and polyphenols) (Li et al., 2007; Shimoda et al., 2008; Venkatachalam and Sathe, 2006). Generally, the moisture content (MC) of fresh walnuts is more than $20 \%$, dry basis (d.b.), after harvesting. Walnuts are susceptible to decay and germination during storage due to high water and fat contents, and high lipase activities (Ma et al., 2013). After harvesting, fresh walnuts must be dried to $8.0 \%$ and $5.0 \%$ (d.b.) MC of whole nuts and kernels, respectively, for long-term storage in ambient environment (Amaral et al., 2003). Therefore, developing an effective drying method for in-shell walnuts is a major postharvest processing concern in the nut industry.

Dehydration reduces water activity and usually extends shelf life of perishable agricultural products. During the past few years, the convective drying, fluidized bed drying, and microwave drying technologies have been studied for several seeds and nuts. For example, Guine et al. (2011) reported the convective drying of pumpkin by different air temperatures, ranging between $30^{\circ} \mathrm{C}$ and $70{ }^{\circ} \mathrm{C}$. HassanBeygi et al. (2009) determined drying characteristics of walnuts during convective drying at air temperatures of $32{ }^{\circ} \mathrm{C}$ and $43{ }^{\circ} \mathrm{C}$ and two air velocities of 1 and $3 \mathrm{~m} / \mathrm{s}$. Ozahi and Demir (2014) conducted a fluidized bed drying test of unshelled pistachio nuts with different hot air velocity, pressure, temperature and moisture content. Silva et al. (2006) developed microwave assisted drying processes for macadamia nuts. Recently, Marra et al. (2010), Pace et al. (2011) and De Bonis et al. (2015) reported the effects of microwave exposure with enhanced heat convection on drying performance. Unfortunately, each of these methods has its limitations in terms of efficiency

\footnotetext{
${ }^{*}$ Corresponding author:

Shaojin Wang, Ph.D, Professor, Northwest A\&F University, College of Mechanical and Electronic Engineering, Yangling, Shaanxi, China. Tel: +86-29 87092319, Fax: +86- 29 87091737, E-mail: shaojinwang@nwsuaf.edu.cn
} 
or cost. For example, hot airflow drying takes a long time and has low energy efficiency, especially during the falling rate periods. A major drawback in microwave drying is the inherent non-uniformity of the electromagnetic field within a microwave cavity and usually in small scale because of a limited penetration depth (Zhang et al., 2006). Thus, it is desirable to develop an effective, practical and economically viable method for drying in-shell walnuts.

Novel thermal treatment technology, such as radio frequency (RF) energy, can directly interact with commodities to generate heat quickly and volumetrically, and thus significantly reduce heating time or raise heating rate so as to avoid quality losses caused by slow heating or overheating in conventional thermal treatments (Marra et al., 2009). Many studies have explored the possibility of using RF energy for disinfesting products (Hou et al., 2014; Wang et al., 2007a, b; Zhang et al., 2015) and pasteurization (Gao et al., 2010; Kim et al., 2012; Michael et al., 2014). RF heating technology combined with vacuum has also been used for drying wood products (Leuca et al., 2014; Liu et al., 2014). Especially recently, Wang et al. (2014) developed hot air-assisted RF (HARF) drying protocols and determined the RF drying uniformity for in-shell macadamia nuts. But this study did not evaluate the nut quality in storage period after RF drying. Since walnut kernels contain substantial quantities of triacylglycerols and polyunsaturated fatty acids, and thus could be susceptible to oxidative and hydrolytic rancidity, commercially viable RF drying treatments must retain walnut quality in a long storage period. Therefore, it's important to develop effective and practical RF drying protocols for in-shell walnuts.

The objectives of this research were to (1) select a suitable electrode gap and hot air temperature for RF drying walnuts, (2) compare the MC changes of walnuts as a function of drying time between the RF drying and hot air (HA) drying, and determine suitability of drying curves using five common kinetic models, and (3) evaluate effects of RF drying on quality and storage stability of walnuts during accelerated shelf life tests.

\section{MATERIALS AND METHODS}

\section{Material and HARF heating system}

Fresh walnuts (Juglans regia L.) with variety of Yi-Ke-Shu were purchased from a local grocery store in Yangling, Shaanxi, China. After dehulling, only the uniform size (the diameter of $0.0356 \pm 0.0025 \mathrm{~m}$ ) nuts were used in this study. To prevent moisture loss during storage, the nut samples were packed and vacuum-sealed into aluminium bags stored in a refrigerator (BD/BC-297KMQ, Midea Refrigeration Division, Hefei, China) at $4 \pm 1{ }^{\circ} \mathrm{C}$ before the tests. The initial MC of walnuts was determined according to a modified AOAC Official Method 925.40 (AOAC, 2002). Walnut samples were placed in a vacuum oven (DZX-6020B, Nanrong Lab equipment Inc., Shanghai, China) at $100 \pm 2^{\circ} \mathrm{C}$ and $21 \mathrm{kPa}$ for $7 \mathrm{~h}$, then the samples were placed into a desiccator with $\mathrm{CaSO}_{4}$ (Calcium sulphate) for cooling, and the sample weight was recorded at room temperature. The average initial MCs were $22.4 \%$, $18.7 \%$, and $20.1 \%$ d.b. for shell, kernel and whole nuts, respectively. Before each test, walnut samples sealed in the bag were placed in an incubator (BSC-150, Boxun Industry and Commerce Co., Ltd, Shanghai, China) for $12 \mathrm{~h}$ to have a uniform initial temperature of $25 \pm 0.5^{\circ} \mathrm{C}$ prior to RF heating.

A $6 \mathrm{~kW}, 27.12 \mathrm{MHz}$ free-running oscillator RF system (SO6B, Strayfield International, Wokingham, UK) associated with a hot air system supplied by a $6 \mathrm{~kW}$ electric heater (Fig. 1) was used to dry walnuts. To improve heating uniformity and drying efficiency of nut samples, forced hot air was added from the air distribution box at the bottom electrode into the RF cavity at a velocity of $1.6 \mathrm{~m} / \mathrm{s}$, as measured by an anemometer (DT-8880, China Everbest Machinery Industry Co., Ltd., Shenzhen, China). The interior of the products was quickly heated by RF energy to the evaporation temperature and the vapour could be forced outwards thus permitting the hot air to remove water from the surface. The RF power coupled into the walnut samples was adjusted by changing the gap between the top and bottom electrodes to achieve an appropriate heating rate.

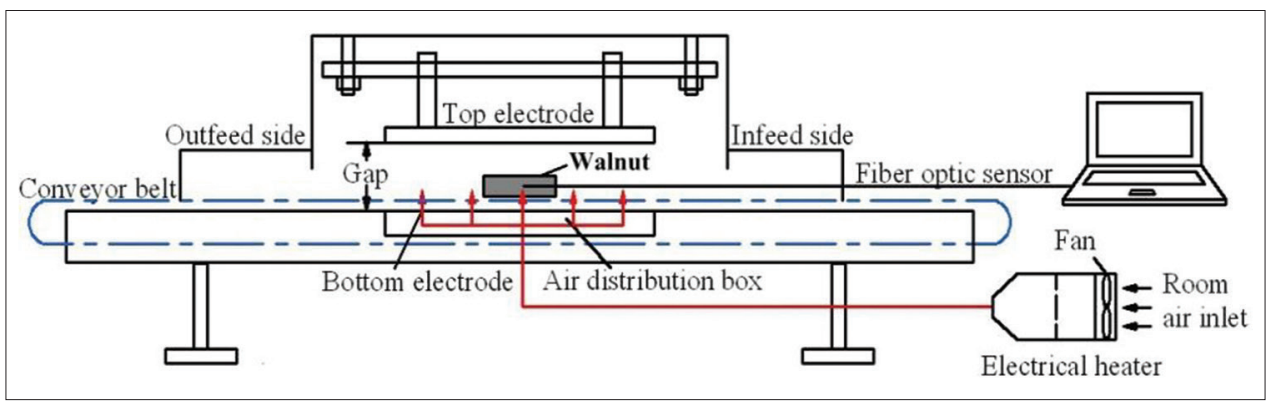

Fig 1. Schematic drawing of the free-running oscillator $6 \mathrm{~kW}, 27.12 \mathrm{MHz}$ RF system showing the plate electrodes, conveyor belt, the hot air system and the fibre optic sensors (Adapted from Wang et al., 2010). 


\section{Determining the electrode gap and hot air temperature} Different electrode gaps in the RF system result in corresponding electric current and thus RF output power. The electric current $(I, \mathrm{~A})$ was displayed on a console of the $\mathrm{RF}$ system, and used to estimate the output power $(P, \mathrm{~kW})$ of the RF system to reach the sample with a relationship $(P=5 \times I-1.5)$ provided by the manufacturer (Jiao et al., 2012). In-shell walnut samples were placed in a plastic container $(30.0 \mathrm{~cm} \times 22.0 \mathrm{~cm} \times 7.0 \mathrm{~cm})$ (Fig. 2) made of polypropylene with perforated side and bottom walls, which allowed hot or room air to pass through the samples for heating or cooling. To determine the appropriate electrode gap, the plastic container filled with and without $1.6 \mathrm{~kg}$ of walnuts was placed on the conveyor above the bottom electrode. After the RF power was turned on without hot air heating and movement, the electric current was recorded when the electrode gap was reduced from 19.0 to $9.0 \mathrm{~cm}$ with a distance interval of $1.0 \mathrm{~cm}$. Each test was repeated twice. Based on the electric current values, three electrode gaps $(17.0,18.0$, and $19.0 \mathrm{~cm})$ were selected for further drying tests.

Different electrode gaps and temperatures of auxiliary hot air are important factors of the RF system to influence heating and drying rates. To determine an effective RF drying protocol for quickly drying and ensuring product quality, three hot air temperatures $\left(40,50\right.$, and $60^{\circ} \mathrm{C}$ ) (Table 1) were chosen as HARF heating tests under the previously selected three electrode gaps. The plastic container loaded with $1.6 \mathrm{~kg}$ of walnut samples was placed on the centre of the bottom electrode and subjected to HARF heating. The sample temperatures at six positions of the container (Fig. 2) were measured using a six-channel fibre-optic temperature sensor system (HQ-FTS-D120, Heqi Technologies Inc., Xian, China) with an accuracy of $\pm 0.5^{\circ} \mathrm{C}$. The probe was inserted into walnut kernels through predrilled holes. Temperatures were sampled every $1 \mathrm{~s}$ and recorded every $4 \mathrm{~min}$ over $60 \mathrm{~min}$. Average and standard deviation values in the temperature of the RF heated samples over the six locations were compared to determine a suitable electrode gap and hot air temperature that might yield minimum sample temperature variations for further RF drying tests.

\section{HARF drying test}

Based on the test results described above, an optimal electrode gap $(18.0 \mathrm{~cm})$ and hot air temperature $\left(50^{\circ} \mathrm{C}\right)$ were selected. The plastic sample container loaded with $1.6 \mathrm{~kg}$ of walnuts was placed on the bottom electrode plate for drying tests. The container was taken out of the RF system every $10 \mathrm{~min}$ in the whole process of the drying test until the sample MC reached about $8.0 \%$ (d.b.). The surface temperature and weight of samples were measured and recorded immediately. The surface temperature of walnuts in the container was measured by an infrared camera (FLIR

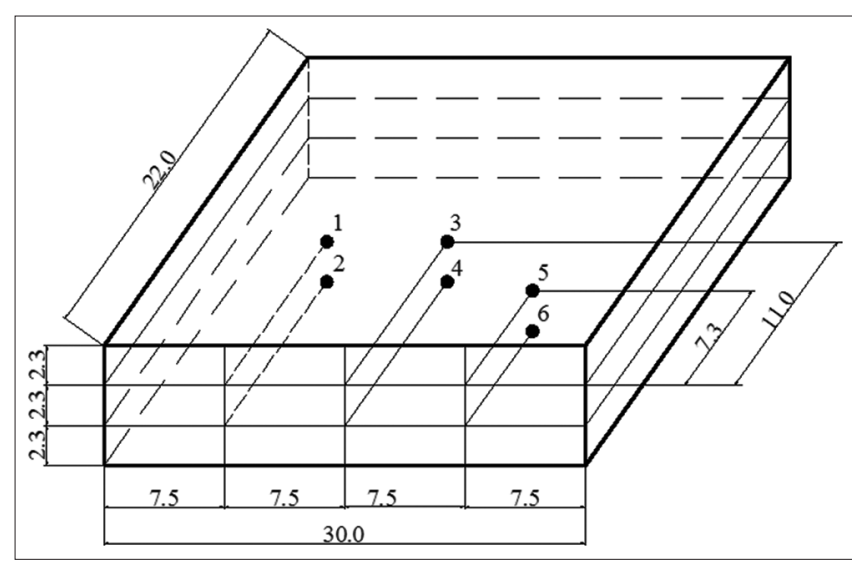

Fig 2. The plastic container with six fibre-optic probe locations for sample temperature measurements (all dimensions are in $\mathrm{cm}$ ).

Table 1: Walnut temperatures during hot air-assisted RF heating as influenced by electrode gaps and air temperatures

\begin{tabular}{lccc}
\hline $\begin{array}{l}\text { Electrode } \\
\text { gap }(\mathbf{c m})\end{array}$ & $\begin{array}{c}\text { Air } \\
\text { temperature } \\
\left({ }^{\circ} \mathbf{C}\right)\end{array}$ & $\begin{array}{c}\text { Average } \\
\text { heating rate } \\
\left({ }^{\circ} \text { C/min) for }\right. \\
\text { the first 20 } \text { min }\end{array}$ & $\begin{array}{c}\text { Sample temperature } \\
\left({ }^{\circ} \mathbf{C} \text {, average } \pm \text { SD }\right) \\
\text { during RF heating } \\
\text { between 20 and } 60 \text { min }\end{array}$ \\
\hline 17.0 & 40 & 2.13 & $76.24 \pm 3.65$ \\
17.0 & 50 & 2.65 & $85.83 \pm 2.94$ \\
17.0 & 60 & 3.30 & $96.90 \pm 2.24$ \\
18.0 & 40 & 1.94 & $71.04 \pm 2.98$ \\
18.0 & 50 & 2.38 & $79.61 \pm 2.72$ \\
18.0 & 60 & 2.72 & $88.72 \pm 3.31$ \\
19.0 & 40 & 1.53 & $64.99 \pm 3.79$ \\
19.0 & 50 & 1.98 & $73.55 \pm 3.49$ \\
19.0 & 60 & 2.57 & $83.01 \pm 2.50$ \\
\hline
\end{tabular}

A300, FLIR Systems AB, Sweden) having an accuracy \pm $2^{\circ} \mathrm{C}$. From each of the thermal images, 35,298 individual surface temperature data points were collected and used for statistical analyses. The sample weight in the container was measured by an electronic balance (PTX-FA210, Huazhi Scientific Instrument, Co., Ltd. Fuzhou, China) with a sensitivity of $0.01 \mathrm{~g}$. Each measurement took less than $1 \mathrm{~min}$, and the samples in the container were placed back into the RF cavity for further heating under the same conditions. The drying tests were conducted in triplicate.

During the drying, the heat generation in walnuts due to absorbed RF energy could be defined as (Wang et al., 2001):

$$
P=2 \pi f \varepsilon_{0} \varepsilon^{\prime \prime} E^{2}
$$

where $P$ is the energy conversion per unit volume $\left(\mathrm{W} / \mathrm{m}^{3}\right)$, $E$ is the electric field strength in the material $(\mathrm{V} / \mathrm{m}), f$ is the frequency of electromagnetic waves $(\mathrm{Hz}), \varepsilon_{0}$ is the permittivity of free space or vacuum $\left(8.854 \times 10^{-12} \mathrm{~F} / \mathrm{m}\right)$, and $\varepsilon^{\prime \prime}$ is the relative dielectric loss factor of walnuts.

In the whole drying, energy exchange could be defined as (Wang et al., 2014): 
$P_{\text {Tem }}=P_{R F}+P_{\text {air }}-P_{\text {vapor }}$

where $P_{\text {Tem }}$ is the net energy accumulated in walnut samples $(\mathrm{W} / \mathrm{kg}), P_{\mathrm{RF}}$ is the energy input due to RF heating $(\mathrm{W} / \mathrm{kg})$, $P_{\text {air }}$ is the energy exchange due to the HA heating (W/ kg), and $P_{\text {vapor }}$ is the energy loss due to moisture evaporation $(\mathrm{W} / \mathrm{kg})$.

\section{Hot air drying test}

The highest temperature $\left(80^{\circ} \mathrm{C}\right)$ in the HARF drying test was selected to study HA only drying and compare with the HARF drying. The walnut surface temperature and weight in the container were measured every 30 min using the same method as described above. The HA drying tests also continued until the $\mathrm{MC}$ reached about $8.0 \%$ (d.b.). The tests were repeated for three times.

\section{Drying kinetics}

Five common drying kinetic models were used for mathematical modelling of the drying curves of walnut samples and listed in Table 2. The parameters of the drying equations were estimated by regression analysis using the Statistical Package for the Social Sciences (SPSS) (version 16.0, SPSS, Inc.). The goodness-of-fit of different models was evaluated with the determination coefficient $\left(R^{2}\right)$, mean relative deviation $(M R D)$, and standard error of estimate (SEE). The moisture ratio (MR) versus time was plotted to obtain the drying rate constant of each model, and is defined as:

$$
M R=\frac{M_{t}-M_{e}}{M_{0}-M_{e}}
$$

where $M R$ is moisture ratio (dimensionless), $M_{t}$ is the MC (\% d.b.) at time $t(\mathrm{~min}), M_{0}$ is the initial MC (\% d.b.), and $M_{e}$ is the equilibrium sample MC estimated to be $1.8 \%$ d.b. by preliminary tests.

The $M R D$ is defined as:

$$
M R D=\frac{1}{N} \sum_{i=1}^{N} \frac{\left|\left(M_{\mathrm{R}}-\hat{M}_{\mathrm{R}}\right)\right|}{M_{\mathrm{R}}}
$$

The SEE is defined as:

Table 2: Kinetic models applied to the drying curves (Silva
et al., 2006; Tarigan et al., 2007)
\begin{tabular}{ll}
\hline Models & Equations \\
\hline Page & $M R=\exp \left(-k t^{n}\right)$ \\
Newton & $M R=\exp (-k t)$ \\
Henderson and Pabis & $M R=a \exp (-k t)$ \\
Logarithmic & $M R=a \exp (-k t)+c$ \\
Wang and Singh & $M R=1+a t+b t^{2}$ \\
\hline
\end{tabular}

$S E E=\sqrt{\frac{\sum_{i=1}^{N}\left(M_{\mathrm{R}}-\hat{M}_{\mathrm{R}}\right)^{2}}{d_{f}}}$

where $M_{R}$ is the measured moisture ratio, $\hat{M}_{R}$ the predicted moisture ratio, $N$ the number of data points, and $d_{\text {f }}$ the degrees of freedom of the regression model (number of data points minus number of constants in the thin layer model).

\section{Quality analyses and storage test}

The quality of walnuts was evaluated during the drying process and after accelerated storage tests, respectively. The peroxide value (PV), free fatty acid (FFA) and colour ( $L$ value) of walnut kernels were selected as major parameters for quality analysis. For drying processes, the quality analysis was conducted at 0,50 , and $100 \mathrm{~min}$, and $0,50,100,150$, 200, and 240 min during HARF drying and HA only drying, respectively. For storage tests, HA and HARF treated walnuts $(400 \mathrm{~g})$ were packed individually in 2 bags and stored in the incubator set to $35 \pm 0.5^{\circ} \mathrm{C}$ with $30 \%$ relative humidity (RH) for 20 days to simulate commercial storage at $4{ }^{\circ} \mathrm{C}$ for 2 years (Wang et al., 2002). The samples were taken out every 10 days for quality evaluations. The tests were conducted in triplicate.

The PV and FFA values were determined using methods $\mathrm{Cd}$ 8-53 and Ca 5a-40 of the American Oil Chemists Society (AOCS, 1998a, b). The detailed measurement procedures and calculations of PV and FFA have been reported in Wang et al. (2001) and Ling et al. (2014).

The colour analysis was performed using a computer vision system (CVS), composed of a lighting system, a Cannon EOS 600 Digital camera with 1800 megapixel resolution and EF-S 18-55 $\mathrm{mm} \mathrm{f}$ /3.5-5.6 Zoom Lens, and a computer with image-processing software. Walnut samples were placed in a plastic Petri dish ( $9 \mathrm{~cm}$ diameter) at the bottom of a shooting tent to capture colour images. The change in kernel colour values was only analysed for $L$ values (Wang et al., 2007b), and an Adobe Photoshop CS3 (Adobe Systems Inc., USA) system was used to obtain colour values $(L)$. Finally, the colour values $(L)$ obtained from Photoshop were converted to CIE LAB $\left(L^{*}\right)$ values using the following equation (Hou et al., 2014; Wang et al., 2007b):

$$
L^{*}=\frac{L}{2.5}
$$

\section{Statistical analysis}

Data were reported as mean \pm standard deviation of replicated measurements. Significant differences $(\mathrm{p}<0.05)$ among means were determined by analysis of variance and 
Tukey's test in the statistical software SPSS 16.0 version (SPSS Inc., Chicago, IL, USA).

\section{RESULTS AND DISCUSSION}

\section{The electric current under different gap}

Fig. 3 shows the relationship between the electrode gap and electric current for the RF treatments with or without loads (walnuts). Without walnuts, the electric current fluctuated in a narrow range around $0.3 \mathrm{~A}$ as electrode gap was varied. With walnuts, electric current almost kept constant around $0.32 \mathrm{~A}$ as electrode gap decreased from $19 \mathrm{~cm}$ to $14 \mathrm{~cm}$ and there after rapidly increased from $0.34 \mathrm{~A}$ to $0.51 \mathrm{~A}$ when the electrode gap decreased from $14.0 \mathrm{~cm}$ to $9.0 \mathrm{~cm}$. Similar trends were also observed by Wang et al. (2010), Gao et al. (2010) and Hou et al. (2014). To obtain acceptable product quality and suitable heating rate, three electrode gaps $(17.0,18.0$, and $19.0 \mathrm{~cm})$ were selected for further tests.

\section{Selection of electrode gap and hot air temperature for HARF drying}

Fig. 4 shows the temperature-time histories of walnuts with three electrode gaps $(17.0,18.0$, and $19.0 \mathrm{~cm})$ when subjected to hot air $\left(40,50\right.$, and $\left.60^{\circ} \mathrm{C}\right)$ assisted RF heating. At the first $40 \mathrm{~min}$ of heating time, the average temperatures rapidly increased with increasing heating time. For a given electrode gap, as hot air temperature increased, the heating rate and the maximum temperature value tended to increase. Since the absorbed RF power was balanced by the latent heat of water evaporation after heating for $40 \mathrm{~min}$, the sample temperature was maintained at a fairly constant value. Finally, the sample temperature began to decline slowly due to reduced RF power absorbed by the walnut samples with the reduced MC. Similar trends were also observed by Wang et al. (2014b) who used HARF drying for in-shell macadamia nuts. To obtain the required drying rate and avoid nut quality degradation, a process that combined an electrode gap of $18.0 \mathrm{~cm}$ with $50^{\circ} \mathrm{C}$ hot air was selected for further drying tests.

\section{Drying curves}

Fig. 5 shows the $\mathrm{MC}$ as function of drying time for the HARF drying. At the first $40 \mathrm{~min}$ of HARF drying, the sample weight or $\mathrm{MC}$ was reduced rapidly and the drying rate reached the maximum level. The drying rate gradually decreased when the drying time increased from $40 \mathrm{~min}$ to 100 min. After RF drying for $100 \mathrm{~min}$, the target MC of whole nuts was achieved to be $8.0 \%$ (d.b.).

Fig. 6 shows a typical drying curve when using hot air at $80^{\circ} \mathrm{C}$. The drying rate was much slower than that in HARF drying, resulting in a longer drying time (240 $\mathrm{min})$ to reach

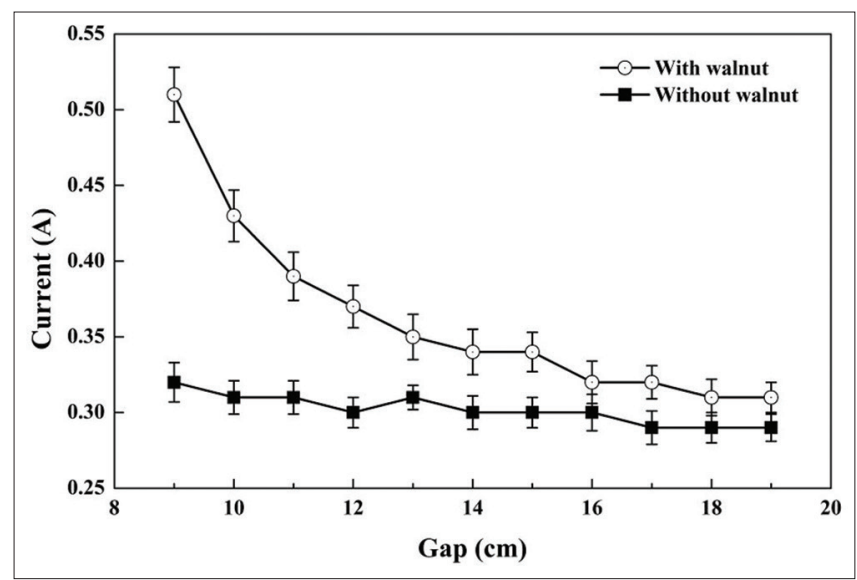

Fig 3. Electric current of the radio frequency system as a function of electrode gap.

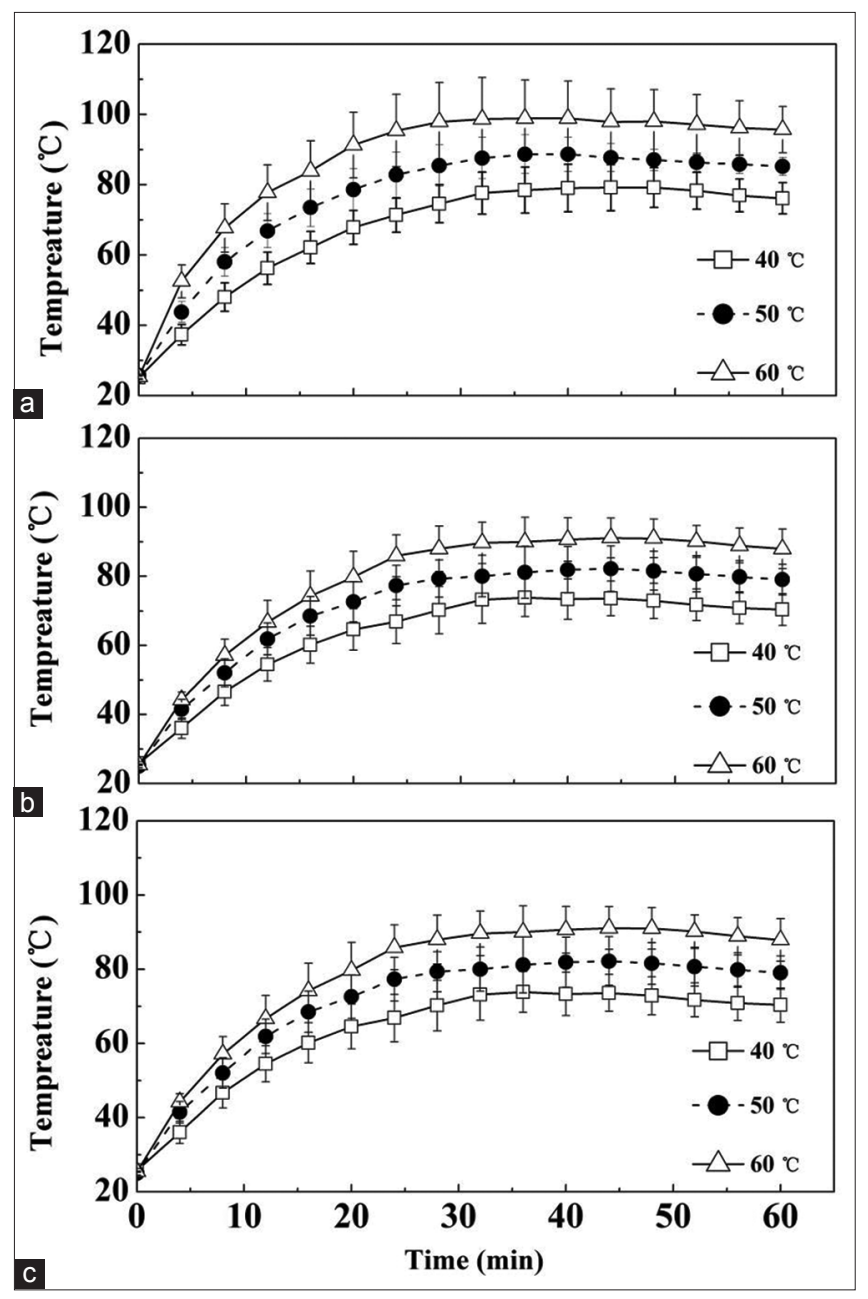

Fig 4. Average and standard deviation values of walnut temperatures over six locations with electrode gaps of $17.0 \mathrm{~cm} \mathrm{(a),} 18.0 \mathrm{~cm}(\mathrm{~b})$, and $19.0 \mathrm{~cm}$ (c) when subjected to hot air $\left(40,50\right.$, and $\left.60^{\circ} \mathrm{C}\right)$ assisted radio frequency drying.

the target $\mathrm{MC}$ of $8.0 \%$ d.b. for whole nuts and $5.0 \%$ d.b. for kernels (Fig. 6a). The sample surface temperature gradually increased with drying time but was always below 

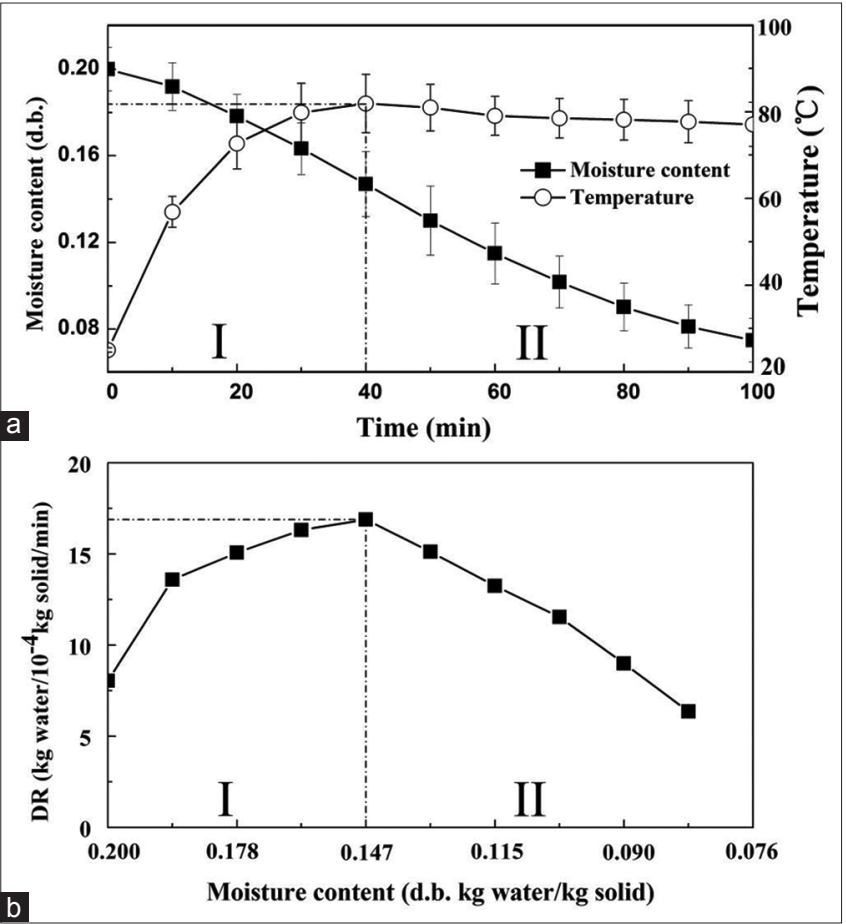

Fig 5. Drying curve (a) with average sample surface temperatures and drying rate $(b)$ when subjected to hot air $\left(50^{\circ} \mathrm{C}\right)$ assisted radio frequency drying with an electrode gap of $18.0 \mathrm{~cm}$
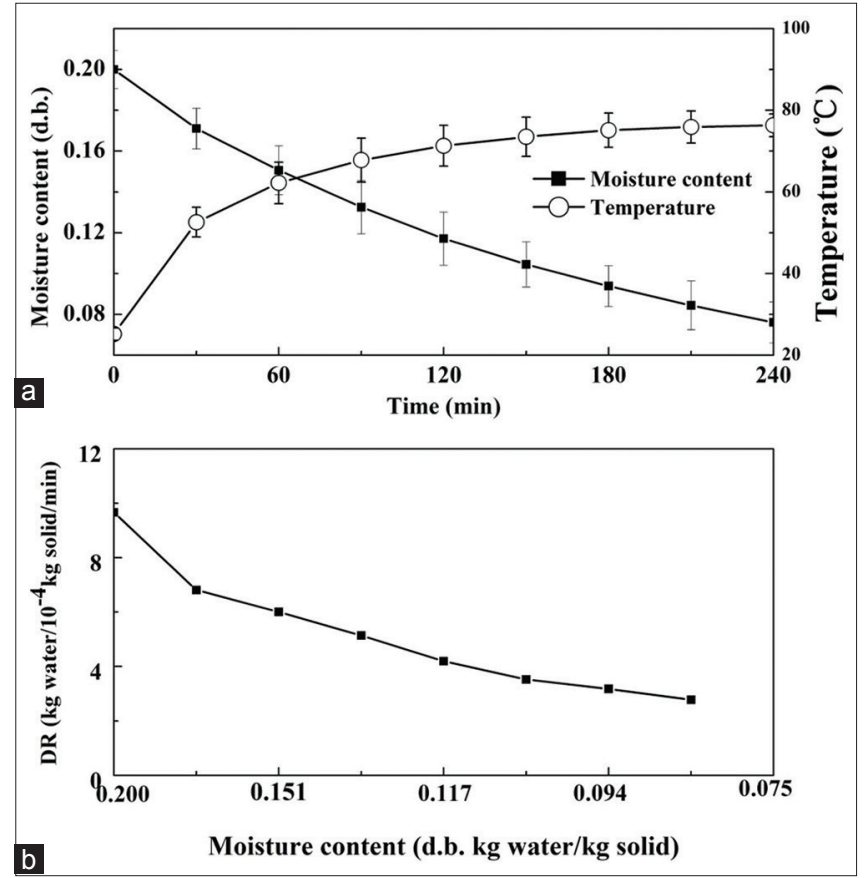

Fig 6. Drying curve (a) and rate (b) when subjected to hot air drying with a temperature of $80^{\circ} \mathrm{C}$.

the hot air set point $\left(80^{\circ} \mathrm{C}\right)$. The drying curve exhibited a typical profile for traditional HA drying (Fig. 6b), and was similar to that observed in industrial convection drying of walnuts (Hassan-Beygi et al., 2009). The HARF drying rate (Fig. 5b) was faster when compared to HA drying alone (Fig. 6), since a positive temperature gradient remained due to RF heating and thus the vapour pressure gradient from the sample centre towards the surface enhanced the drying process (Feng et al., 2001; Wang et al., 2014b).

The RF drying process could be divided into two stages (Fig. 6): stage $\mathrm{I}$ is an acceleration drying stage (from $0 \mathrm{~min}$ to $40 \mathrm{~min}$ ) when the walnut temperature gradually reached to a maximum value; stage II is a deceleration drying stage (from $40 \mathrm{~min}$ to $100 \mathrm{~min}$ ) when walnut temperatures were maintained stably. At stage I, since evaporation was still low as the drying process began, the energy gained from RF and hot air was higher than the energy loss for moisture vaporization, and the nut sample temperatures increased from an initial value $\left(25^{\circ} \mathrm{C}\right)$ to a maximum value $\left(81.9^{\circ} \mathrm{C}\right)$ (Fig. $\left.5 \mathrm{a}\right)$. However, with increasing sample temperature and evaporation rate, the heating rate gradually decreased (Fig. 5b). During this stage I, the RF heating contributed the greatest energy due to the high loss factor of high moisture nut samples (Wang et al., 2003). At stage II, heat loss from water evaporation was balanced with input RF energy, so the sample temperature remained almost stable $\left(P_{\text {tem }} \approx 0\right)$. In addition, with the increase of the drying time, the drying rate was gradually reduced due to the continuous moisture loss in walnut samples. A similar result was found in RF drying of in-shell almonds and macadamia nuts (Gao et al., 2010; Wang et al., 2014b).

\section{Drying kinetics of HARF heated walnuts}

The MR versus drying time obtained from HARF drying was fitted with the five kinetic models. The model parameters were determined by applying the nonlinear regression to obtain data as listed in Table 3. The results of these models include the estimated values and standard deviations of the model parameters with determination coefficient $\left(R^{2}\right)$, mean relative deviation $(M R D)$, and standard error of estimate (SEE). The best model was the Page model, with $R^{2}, M R D$ and $S E E$ values of $0.998,0.016$, and 0.094 , respectively. On the other hand, the model with the worst fit was that of Newton, with $R^{2}$ of 0.967 . Thus, the Page model is listed below to best describe the drying kinetics of nuts under HARF heating:

$$
M R=\exp \left(-0.002 t^{1.369}\right)
$$

\section{Quality analysis of nuts during drying and storage}

Table 4 shows the results of walnut quality evaluations during the drying periods. With increasing drying time, the $P V, F F A$ and kernel colour $L$-values fluctuated in a narrow 
range both for HA and HARF dried nuts. A significant difference $(\mathrm{P}<0.05)$ was only observed for HA drying time increased to more than $200 \mathrm{~min}$. There was no significant difference between HA and HARF dried nuts for the selected quality attributes (PV, FFA and kernel colour $L$-values) during the same drying time ( $\mathrm{P}>0.05)$. However, the final mean PV value of HARF dried walnuts significantly lower than HA dried walnuts, since HARF drying rate was faster than that in HA drying.

Table 5 shows the result of walnuts storage quality characteristics after HA drying and HARF drying. During entire accelerated shelf life storage test, the PV values of HARF dried walnuts significantly lower than HA dried walnuts $(\mathrm{P}<0.05)$. However, there was no significant difference between HA and HARF dried nuts for FFA and kernel colour $L$-values during the storage time $(\mathrm{P}>0.05)$. For both HA and HARF dried walnuts, the final PV, FFA and kernel colour $L$-values in the study remained within the acceptable range (PV $<1.0 \mathrm{meq} / \mathrm{kg}, \mathrm{FFA}<0.6 \%$ and $L^{*}>40$ ) used by industry for good walnut quality (Lindsay,

Table 3: Kinetic models for hot air-assisted RF drying of in-shell walnuts

\begin{tabular}{lcccccccc}
\hline Model & $\boldsymbol{R}^{2}$ & MRD & SEE & $\boldsymbol{k}$ & $\boldsymbol{n}$ & $\boldsymbol{a}$ & $\boldsymbol{b}$ & $\boldsymbol{c}$ \\
\hline Page & 0.998 & 0.017 & 0.095 & 0.002 & 1.369 & & & \\
Newton & 0.967 & 0.065 & 1.414 & 0.010 & & & & \\
Henderson & 0.981 & 0.048 & 0.315 & 0.012 & & 1.064 & & \\
and Pabis & & & & & & & & \\
Logarithmic & 0.994 & 0.028 & 0.179 & 0.004 & 2.299 & -1.268 \\
Wang and & 0.991 & 0.039 & 0.232 & & -0.001 & 0.063 & \\
Singh & & & & & & & & \\
\hline
\end{tabular}

private communication, 1999). Similar results were also observed by Wang et al. (2007a, b) for RF disinfested walnuts.

\section{CONCLUSIONS}

This study showed that HARF treatments could strongly reduce the drying time of walnut samples compared to HA heating alone. Five common drying kinetic models were used for the mathematical modelling of the drying curves, and the Page model provided the best fit for HARF drying data. Walnut quality was not affected significantly by the RF treatments because quality parameters (PV, FFA, and colour) of treated walnuts remained within limits acceptable to the nut industry. Further studies should be conducted on the optimization of RF treatment protocols using computer simulation to improve the drying process efficiency and scale-up for industrial applications.

\section{ACKNOWLEDGMENTS}

This research was conducted in the College of Mechanical and Electronic Engineering and Sino-US Joint Research Centre for Food Safety, and supported by research grants from General Program of National Natural Science Foundation of China (No.31371853), Open Fund from Zhejiang Academy of Agricultural Sciences, and Program of Introducing International Advanced Agricultural Science and Technologies (948 Program) of Ministry of Agriculture of China (2014-Z21). The authors thank Bo

Table 4: Quality characteristics (mean \pm SD) of walnuts as influenced by drying time when subjected to hot air (HA) and hot air-assisted RF (HARF) drying

\begin{tabular}{|c|c|c|c|c|c|c|}
\hline \multirow{2}{*}{$\begin{array}{l}\text { Drying } \\
\text { time (min) }\end{array}$} & \multicolumn{2}{|c|}{$\mathrm{PV}^{1}$ (meq/kg) } & \multicolumn{2}{|c|}{ FFA $^{1}(\%)$} & \multicolumn{2}{|c|}{ Kernel colour (L-value) ${ }^{2}$} \\
\hline & HA & HARF & HA & HARF & HA & HARF \\
\hline 0 & $0.31 \pm 0.09 a A^{3}$ & $0.31 \pm 0.09 a A$ & $0.20 \pm 0.08 \mathrm{aA}$ & $0.20 \pm 0.08 \mathrm{aA}$ & $53.87 \pm 1.80 \mathrm{aA}$ & $53.87 \pm 1.85 \mathrm{aA}$ \\
\hline 50 & $0.34 \pm 0.07 a A$ & $0.32 \pm 0.07 \mathrm{aA}$ & $0.22 \pm 0.04 \mathrm{aA}$ & $0.21 \pm 0.07 a A$ & $53.62 \pm 1.51 \mathrm{aA}$ & $52.88 \pm 2.32 \mathrm{aA}$ \\
\hline 100 & $0.35 \pm 0.10 \mathrm{aA}$ & $0.34 \pm 0.08 \mathrm{aA}$ & $0.24 \pm 0.06 \mathrm{aA}$ & $0.22 \pm 0.04 \mathrm{aA}$ & $52.45 \pm 1.60 \mathrm{aA}$ & $51.40 \pm 1.21 \mathrm{aA}$ \\
\hline 150 & $0.39 \pm 0.07 a b$ & - & $0.26 \pm 0.09 a$ & - & $51.87 \pm 2.12 a$ & - \\
\hline 200 & $0.52 \pm 0.04 a b$ & - & $0.34 \pm 0.07 a$ & - & $50.65 \pm 1.73 a$ & - \\
\hline 240 & $0.58 \pm 0.08 b$ & - & $0.35 \pm 0.10 a$ & - & $50.24 \pm 1.42 a$ & - \\
\hline
\end{tabular}

${ }^{1}$ Accepted peroxide value (PV) and free fatty acid (FFA) values for good quality are less than $1.0 \mathrm{meq} / \mathrm{kg}$ and $0.6 \%$, respectively. ${ }^{2} \mathrm{~L}$-value (lightness): $0=\mathrm{Black}$ and $100=$ White; good quality $\geq 40 .{ }^{3}$ Mean values are not significantly different $(p>0.05)$ for the same lower case letters within a column among the drying time, and for the same capital letters within a row among the heating treatments

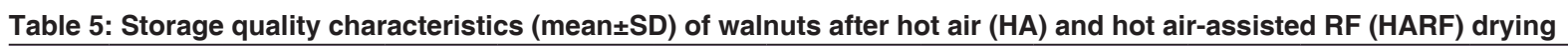

\begin{tabular}{|c|c|c|c|c|c|c|}
\hline \multirow{2}{*}{$\begin{array}{l}\text { Storage } \\
\text { time (d) }\end{array}$} & \multicolumn{2}{|c|}{$(\mathrm{meq} / \mathrm{kg})^{1} \mathrm{PV}$} & \multicolumn{2}{|c|}{ FFA $^{1}(\%)$} & \multicolumn{2}{|c|}{ Kernel colour (L-value) ${ }^{2}$} \\
\hline & HA & HARF & HA & HARF & HA & HARF \\
\hline 0 & $0.58 \pm 0.08 a A^{3}$ & $0.34 \pm 0.08 a B$ & $0.35 \pm 0.10 \mathrm{aA}$ & $0.22 \pm 0.04 a A$ & $50.24 \pm 1.42 a A$ & $51.40 \pm 1.21 \mathrm{aA}$ \\
\hline 10 & $0.71 \pm 0.10 \mathrm{aA}$ & $0.53 \pm 0.09 \mathrm{aB}$ & $0.38 \pm 0.09 a A$ & $0.21 \pm 0.08 a A$ & $50.10 \pm 0.91 \mathrm{aA}$ & $50.78 \pm 2.33 a A$ \\
\hline 20 & $0.93 \pm 0.04 \mathrm{bA}$ & $0.78 \pm 0.07 \mathrm{bB}$ & $0.37 \pm 0.13 a A$ & $0.24 \pm 0.03 a A$ & $49.81 \pm 1.25 \mathrm{aA}$ & $49.75 \pm 1.70 \mathrm{aA}$ \\
\hline
\end{tabular}

${ }^{1}$ Accepted peroxide value and fatty acid values for good quality are less than $1.0 \mathrm{meq} / \mathrm{kg}$ and $0.6 \%$, respectively. ${ }^{2} \mathrm{~L}$-value (lightness): $0=\mathrm{Black}$ and $100=$ White; good quality $\geq 40 .{ }^{3}$ Mean values are not significantly different $(p>0.05)$ for the same lower case letters within a column among the storage time, and for the same capital letters within a row among the heating treatments 
Ling, Kun Wang, Long Chen and Rui Li for their help in conducting experiments.

\section{Author contribution}

B. Zhang conducted drying protocol development tests and data analysis. A. Zheng, L. Zhou and Z. Huang helped the RF system operations and product quality evaluations. $\mathrm{S}$. Wang was the project director and guided the overall experimental design and interpretation of hot air-assisted RF drying results.

\section{REFERENCES}

AOAC. 2002. Official Methods of Analysis, $15^{\text {th }}$ ed. Association of Official Analytical Chemists, Gaithersburg.

AOCS. 1998a. Official method Cd 8-53: Peroxide value acetic acidchloroform method. In: Official Methods and Recommended Practices of the American Oil Chemists, AOCS, Urbana, IL.

AOCS. 1998b. Official method Ca 5a-40: Free fatty acids. In: Official Methods and Recommended Practices of the American Oil Chemists, AOCS, Urbana, IL.

Amaral, J. S., S. Casal, J. A. Pereira, R. M. Seabra and B. P. P. Oliveira. 2003. Determination of sterol and fatty acid compositions, oxidative stability, and nutritional value of six walnut (Juglans regia L.) cultivars grown in Portugal. J. Agric. Food Chem. 51(26): 7698-7702.

De Bonis, M. V., P. Caccavale and G. Ruocco. 2015. Convective control to microwave exposure of moist substrates. Part I: Model methodology. Int. J. Heat Mass Tran. 86(28): 943-949.

FAOSTAT. 2014. Food and Agriculture Organization. Available from: http://faostat3.fao.org/browse/Q/*/E.

Feng, H., J. Tang, R. P. Cavalieri and O. A. Plumb. 2001. Heat and mass transport in microwave drying of porous materials in a spouted bed. AICHE J. 47(7): 1499-1512.

Gao, M., J. Tang, Y. Wang, J. Powers and S. Wang. 2010. Almond quality as influenced by radio frequency heat treatments for disinfestation. Postharvest Biol. Technol. 58(3): 225-231.

Guine, R. P. P., S. Pinho and M. J. Barroca. 2011. Study of the convective drying of pumpkin (Cucurbita maxima). Food Bioprod. Process. 89(C4): 422-428.

Hassan-Beygi, S. R., M. Aghbashlo, M. H. Kianmehr and J. Massah. 2009. Drying characteristics of walnut (Juglans regia L.) during convection drying. Int. Agrophys. 23(2): 129-135.

Hou, L. X., B. Ling and S. J. Wang. 2014. Development of thermal treatment protocol for disinfesting chestnuts using radio frequency energy. Postharvest Biol. Technol. 98: 65-71.

Jiao, S., J. A. Johnson, J. Tang and S. Wang. 2012. Industrial-scale radio frequency treatments for insect control in lentils. J. Stored Prod. Res. 48: 143-148.

Kim, S. Y., H. G. Sagong, S. H. Choi, S. Ryu and D. H. Kang. 2012. Radio-frequency heating to inactivate Salmonella Typhimurium and Escherichia coli O157: $\mathrm{H} 7$ on black and red pepper spice. Int. J. Food Microbiol. 153(1): 171-175.

Leuca, T., M. Laza, L. Bandici, G. Cheregi, G. M. Vasilescu and O. M. Drosu. 2014. FEM-BEM analysis of radio frequency drying of a moving wooden piece. Rom. Rev. Tech. Sci. Elect. Eng. Ene. Serie. 59(4): 361-370.

Li, L., R. Tsao, R. Yang, J. K. G. Kramer and M. Hernandez. 2007. Fatty acid profiles, tocopherol contents, and antioxidant activities of heartnut (Juglans ailanthifolia Var. Cordiformis) and persian walnut (Juglans regia L.). J. Agric. Food Chem. 55(4): 1164-1169.

Ling, B., L. X. Hou, R. Li and Wang, S. J. 2014. Thermal treatment and storage condition effects on walnut paste quality associated with enzyme inactivation. LWT-Food Sci. Technol. 59(2), 786-793.

Liu, H. H., L. Yang, Y. C. Cai, K. Hayashi and K. F. Li. 2014. Distribution and variation of pressure and temperature in wood cross section during radio-frequency vacuum (RF/V) drying. Bioresources. 9(2), 3064-3076.

Ma, Y. P., X. G. Lu, X. H. Liu and H. L. Ma. 2013. Effect of Co-60gamma-irradiation doses on nutrients and sensory quality of fresh walnuts during storage. Postharvest Biol. Technol. 84: 36-42.

Marra, F., M. V. De Bonis and G. Ruocco. 2010. Combined micorwaves and convection heating: A conjugate approach. J. Food Eng. 97(1): 31-39.

Marra, F., L. Zhang and J. G. Lyng. 2009. Radio frequency treatment of foods: Review of recent advances. J. Food Eng. 91(4): 497508.

Michael, M., R. K. Phebus, H. Thippreddi, J. Subbiah, S. L. Birla and K. A. Schmidt. 2014. Validation of radio-frequency dielectric heating system for destruction of Cronobacter sakazakii and Salmonella species in nonfat dry milk. J. Dairy Sci. 97(12): 7316-7324.

Ozahi, E. and H. Demir. 2014. Presentation of a test rig with its testal procedure and uncertainty analysis of measurements for batch type fluidized bed drying of corn and unshelled pistachio nut. Measurement. 53: 117-127.

Pace, M., M. V. De Bonis, F. Marra and G. Ruocco. 2011. Characterization of a combination oven prototype: Effects of microwave exposure and enhanced convection to local temperature rise in a moist substrate. Int. Commun. Heat Mass. 38(5): 557-564.

Shimoda, H., J. Tanaka, M. Kikuchi, T. Fukuda, H. Ito, T. Hatano and T. Yoshida. 2008. Walnut polyphenols prevent liver damage induced by carbon tetrachloride and D-galactosamine: Hepatoprotective hydrolyzable tannins in the kernel pellicles of walnut. J. Agric. Food Chem. 56(12): 4444-4449.

Silva, F. A., A. Marsaloli, G. J. Maximo, M. Silva and L. A. G. Goncalves. 2006. Microwave assisted drying of macadamia nuts. J. Food Eng. 77(3): 550-558.

Tarigan, E., G. Prateepchaikul, R. Yamsaengsung, A. Sirichote and P. Tekasakul. 2007. Drying characteristics of unshelled kernels of candle nuts. J. Food Eng. 79(3), 828-833.

Venkatachalam, M. and S. K. Sathe. 2006. Chemical composition of selected edible nut seeds. J. Agric. Food Chem. 54(13): 4705-4714.

Wang, S., J. N. Ikediala, J. Tang, J. D. Hansen, E. Mitcham, R. Mao and B. Swanson. 2001. Radio frequency treatments to control codling moth in in-shell walnuts. Postharvest Biol. Technol. 22(1): 29-38.

Wang, S., A. Monzon, J. A. Johnson, E. J. Mitcham and J. Tang. 2007a. Industrial-scale radio frequency treatments for insect control in walnuts I: Heating uniformity and energy efficiency. Postharvest Biol. Technol. 45(2): 240-246.

Wang, S., M. Monzon, J. A. Johnson, E. J. Mitcham and J. Tang. 2007b. Industrial-scale radio frequency treatments for insect control in walnuts II: Insect mortality and product quality. Postharvest Biol. Technol. 45(2): 247-253.

Wang, S., J. Tang, R. Cavalieri and D. Davis. 2003. Differential heating of insects in dried nuts and fruits associated with radio frequency 
and microwave treatments. T. ASABE. 46(4): 1175-1184.

Wang, S., J. Tang, J. A. Johnson, E. Mitcham, J. D. Hansen, R. P. Cavalieri, J. Bower and B. Biasi. 2002. Process protocols based on radio frequency energy to control field and storage pests in in-shell walnuts. Postharvest Biol. Technol. 26(3): 265-273.

Wang, S., G. Tiwari, S. Jiao, J. A. Johnson and J. Tang. 2010. Developing postharvest disinfestation treatments for legumes using radio frequency energy. Biosyst. Eng. 105(3): 341-349.

Wang, Y. Y., L. Zhang, M. X. Gao, J. Tang and S. J. Wang. 2014a. Pilot-scale radio frequency drying of macadamia nuts: Heating and drying uniformity. Dry. Technol. 32(9): 1052-1059.

Wang, Y. Y., L. Zhang, J. Johnson, M. X. Gao, J. M. Tang, J. R. Powers and S. J. Wang. 2014b. Developing hot air-assisted radio frequency drying for in-shell Macadamia nuts. Food Bioprocess Technol. 7: 278-288.

Zhang, M., J. Tang, A. S. Mujumdar and S. Wang, 2006. Trends in microwave-related drying of fruits and vegetables. Trends Food Sci. Technol. 17(10): 524-534.

Zhang, P. Z., H. K. Zhu and S. Wang. 2015. Experimental evaluations of radio frequency heating in low-moisture agricultural products. Emirates J. Food Agric. 27(9), 662-668. 